\title{
Teoría y Política Económica. Ensayos en honor al profesor Dr. Julio H. G. Olivera
}

Víctor A. Beker y Guillermo J. Escudé (Compiladores), EUDEBA, Buenos Aires. Marzo de 2019

Carlos A. Beltrán

Director de la Revista Ciencias Económicas, Facultad de Ciencias Económicas, Universidad Nacional del Litoral, Argentina

De entre las diferentes estrategias que existen para homenajear a un autor, en este caso un gran maestro fallecido en 2016, los compiladores eligieron convocar a algunos de los alumnos y discípulos del homenajeado, para que escribieran un artículo relacionado al campo de trabajo de cada uno de ellos, precedido por una breve remembranza de su relación con el Dr. Olivera. Ello se plasmó en el libro que hoy tenemos entre manos. Se trata de diez artículos escritos por doce entre alumnos y discípulos.

En la parte I, Metodología económica, fueron incluidos tres artículos: «Teoría del caos y teoría económica», de Víctor Beker, «Qué es una ley económica», de Jorge Fernández Pol, y «Un modelo de negociación empresario-sindical con instancia arbitral», de Fernando Tow.

En la parte II, Macroeconomía y teoría monetaria, también se incluyeron tres contribuciones: «Vista panorámica de la macroeconomía moderna desde sus inicios», de Guillermo Calvo, «Dotaciones pasivas, dinero pasivo y estabilidad walrasiana del equilibrio», de Omar Chisari y Juan Mercatante, y «Una reevaluación de la hipótesis estructural de la inflación», de Saúl Keifman.

En la parte III, Crecimiento económico, aparecen compilados tres artículos: «Progreso social y bienestar», de Luisa Montuschi, «Trampas del crecimiento argentino en las últimas décadas. En pos de claves inter- 
pretativas», de Javier Lindenboim, y «El problema de la primarización en la economía argentina. La dinámica del modelo extractivo en la posconvertibilidad», de Tomás Palmisano y Miguel Teubal.

Por último, en la parte IV, La economía como ciencia social, aparece el artículo «Un marco general para la ciencia de la sociedad humana», de Guillermo Escudé.

Considero que resultaría ocioso hablar del mérito de las diez contribuciones que constituyen el librohomenaje. Como se observa, los temas son variados y escritos con gran rigor por plumas ilustradas. LoS autores tienen distintas trayectorias y pluralidad de opiniones. Era eso precisamente lo que buscaba y generaba Julio Olivera. Tenía una exigencia básica fundamental: consistencia lógica de los argumentos y rigor científico. Más allá de ello, absoluta libertad. Eso permitía generar creadores más que seguidores. Le gustaba actuar como el sembrador despreocupado del Nuevo Testamento que esparcía amplia y generosamente la semilla sabiendo que alguna parte de ella no sería pisoteada en el camino, ni devorada por las aves, ni ahogada por la maleza, sino que tarde o temprano produciría frutos.

Ya convencidos de la utilidad de leer el libro que estamos comentando, argumentaré de aquí en más lo enriquecedor y gratificante que resulta leer al Dr. Olivera. Pienso que será muy fácil convencerlos.

Como es bien conocido, el Dr. Olivera, a quien nada de lo económico le resultaba extraño, hizo valiosas contribuciones que se concretaron en estudios sobre dinámica de la distribución del ingreso, equilibrio monetario y ajuste internacional, estructuralismo latinoamericano, la universidad como unidad de producción, inflación estructural y política financiera, crecimiento económico y seguridad jurídica, reforma del sistema monetario internacional, devaluaciones finitas, el comercio como sucedáneo perfecto de la movilidad de factores y un largo etcétera. Todos ellos, escritos con proverbial concisión, elegancia, erudición y rigor matemático.

Se puede afirmar que entre los economistas argentinos hay un antes y un después de Olivera.
Actualmente, sus orgullosos discípulos ocupan lugares de distinción y privilegio intelectual en distintas universidades, centros de investigación y prestigiosas instituciones tanto nacionales como internacionales.

Creo que presto oídos a un consejo de John Stuart Mill que decía que no es buen economista quien sólo es economista. Además de su sólida y brillante formación en economía, es envidiable su adiestramiento en matemáticas, disciplinas en las que fue un perseverante y entusiasta autodidacta. Recordemos que su título académico fue Doctor en Derecho y Ciencias Sociales.

Según opiniones generalizadas de exalumnos, colegas y otras respetadas voces, el Dr. Olivera en sus clases, seminarios, disertaciones y artículos científicos, desplegaba un estilo, que puede ser calificado como preciosista. Era enemigo de lo barroco. La capacidad de persuasión de su discurso se basaba en cualidades tales como su coherencia lógica, amplitud de visión, perspicacia interpretativa, relevancia valorativa, fuerza retórica, belleza y consistencia argumentativa. Pulcro, detallista hasta la obsesión, crítico pero propositivo y plenamente consciente que la verdad tiene sus días y sus noches. Nos obligaba a todos a elevar el nivel de la discusión, creándonos insaciables curiosidades. Practicante de la esgrima tanto a nivel deportivo como intelectual. En sus escritos no sobra ni falta una palabra, ini siquiera una coma! Me atrevo a definirlo como un «relojero» de la ciencia económica. Mutatis mutandis, un Borges de la literatura económica, ciencia a la que gustaba definir como hermenéutica social y que en su aplicación práctica está regida por la ética.

Era poseedor de una persuasiva sencillez, de un brillo no exento de fino humor y evitaba caer en prisiones conceptuales. Le encantaba distinguir el buen grano de la paja y entregaba esta última al fuego purificador. Fue defensor de los valores éticos de una sociedad abierta.

Fue autor de más de un centenar de artículos técnicos, muchos de los cuales fueron publicados 
en revistas científicas internacionales como The Journal of Political Economy, The Economic Journal, Econométrica, Revue d'Économie Politique, Quarterly Journal of Economics, Weltwirtschaftliches Archiv, Journal of Money, Credit and Banking, Kredit und Kapital, Journal of Development Economics Kyklos.

Los compiladores del libro presentan en las páginas 12 y 13 un listado de sus principales publicaciones.

Ocupó importantísimos cargos en su larga y aquilatada existencia. Se desean destacar los siguientes:

- Subgerente general del Banco Central de la República Argentina a cargo de la dirección de los estudios e investigaciones económicas en el período 1959-1962.

- Secretario de Ciencia y Tecnología de la Nación entre octubre de 1973 y septiembre de 1974.

- Rector de la Universidad de Buenos Aires, por elección de la Asamblea Universitaria (1962-1965).

- Director del Instituto de Investigaciones Económicas de la Facultad de Ciencias Económicas (UBA) desde 1961 y hasta su muerte (2016).

- Miembro del Consejo para la Consolidación de la Democracia desde 1985 hasta 1989 (presidencia de Raúl Alfonsín).

- Miembro fundador de la Asociación Argentina de Economía Política, la que presidió entre 1957 y 1968. Integrante de la Academia Nacional de Ciencias Económicas, de la que fue vicepresidente desde 1973 a 1979 y presidente en los períodos 1989-1991 y 2001-2003; académico de número de la Academia Nacional de Derecho y Ciencias Sociales de Buenos Aires; miembro titular de la Academia Nacional de Ciencias de Buenos Aires; miembro del grupo consultivo del Consejo Nacional de Investigaciones Científicas y Técnicas (Conicet).

Como era de esperar recibió importantes premios, entre ellos el Premio Bunge y Born a la Investigación Científica, el Premio Fundación Ovidio Giménez, el Premio Alejandro E. Shaw en Economía, el Premio
Konex de Platino en la categoría «Teoría Económica» y el Premio Konex de Brillante del año 2006. Fue varias veces consultado por la Real Academia de las Ciencias de Suecia en oportunidad de otorgarse el Premio Nobel de Economía y, a su vez, fue propuesto para tan importante galardón en los años 2000 y 2004.

Muchas de sus ideas alcanzaron sonoridad. Entre sus contribuciones más importantes se podría destacar su teoría no monetaria de la inflación y sus modelos de dinero pasivo. Respecto de la primera, cuestionó algunas conclusiones elaboradas por la economía neoclásica acerca de la típica división entre un sector real y un sector monetario, en el que el primero de ellos explicaba los precios relativos y el segundo los precios monetarios. Como bien sintetiza el Prof. V. Beker, ante un cambio en la estructura de la demanda de la economía se genera un cambio en los precios relativos. Si los precios fueran absolutamente flexibles, algunos precios monetarios subirían y otros bajarían, manteniéndose inalterado el nivel de precios. Sin embargo, si los precios monetarios son inflexibles a la baja, el cambio de precios relativos solo puede producirse mediante el incremento de aquellos cuya demanda ha aumentado, arrastrando a sus complementarios y sustitutos, mientras que el resto de los precios monetarios permanecerá sin cambios. Se producirá, entonces, un aumento en el nivel de precios generado por un cambio de precios relativos, contrariamente a lo sostenido por la dicotomía neoclásica. La inflación puede estar originada así en un fenómeno no monetario (o sea, real). Entre los diversos artículos que conforman el libro, es imperioso destacar el valioso aporte que realiza Saúl Keifman, quien en «Una reevaluación de la hipótesis estructural de la inflación» nos invita a seguir meditando en este tema tan originalmente planteado por Olivera.

En la segunda idea-fuerza se refirió a la necesidad de que la oferta monetaria sea endógena, si los precios, los salarios o el tipo de cambio nominales son fijados exógenamente. El conocido «efecto Olivera-Tanzi» mostró que el déficit fiscal 
no es (o era) el causante de la inflación, sino al revés, debido a los rezagos entre el momento en que se efectúan los gastos públicos y la percepción de los ingresos fiscales. En igual sentido, la cantidad de dinero no generaba los aumentos de precios, sino que la inflación provocaba la emisión de nuevo dinero («el dinero pasivo») para mantener el mismo nivel de gastos expresado en los precios nominales más altos.

Por último, en lo personal y dado que el estilo del libro que estamos comentando no sólo habilita, sino que también lo estimula, me permitiré hacer una breve remembranza del Dr. Olivera. Lamentablemente, yo no estuve entre sus alumnos y por lo tanto no pude gozar asistiendo a la materia «Moneda, Crédito y Bancos» ni a los seminarios semestrales que dictó durante varios años en la FCE de la Universidad de Buenos Aires. Pero afortunadamente lo vi actuar en distintos ámbitos, especialmente en los Congresos de la Asociación Argentina de Economía Política. Tuve dos encuentros personales con él. El primero fue en el Congreso Anual de dicha Asociación, en Río Tercero en el año 1978. Hacía unos pocos años que había terminado mi carrera de grado en la FCE de la UNL. Lo invité para que viniese a dar una conferencia a la UNL. Me agradeció y procedió a tomar nota de mis datos personales. Desplegó un sobre que tenía a mano, trazó algunas rayas y con un lápiz realizó algunos garabatos. Inmediatamente me di cuenta de que había anotado mis datos en forma... taquigráfica. Durante el Congreso lo vi siempre muy cerca de los jóvenes economistas a quienes escuchaba en sus presentaciones y alentaba a seguir trabajando. En mi caso, y como comentarista de un excelente trabajo de Luisa Montuschi, se dignó escucharme y al finalizar, generosamente me felicitó. Allí me formé una primera idea, la que fui coloreando a lo largo de anécdotas y vivencias que escuché durante todos estos años. No exagero si afirmo que entre los economistas era un personaje de leyenda, un mito viviente, una persona entrañable.

El segundo contacto personal fue en octubre de 2006 en el Instituto de Investigaciones Económicas de la FCE-UBA en oportunidad de acercarle la Resolución del título de Doctor Honoris Causa otorgado por la Universidad Nacional del Litoral. Acompañado por otros docentes, la ocasión fue propicia para reflexionar sobre distintas cuestiones. Hizo gala de un conocimiento enciclopédico pero sintético. Ratifique aquello de «que la síntesis es una característica de las personas inteligentes». En uno de los diversos temas de conversación apareció la cuestión de la objetividad en la ciencia, especialmente la economía. Como buen esgrimista «a la cual consideraba que era como el ajedrez pero a la velocidad de la luz», respondió sin dilaciones, pero con vehemencia que siempre debíamos esforzarnos por ser objetivos.

He leído y releído parte de su vasta obra. Me he enriquecido sobremanera de esa experiencia. Me considero un discípulo virtual. No puedo menos que recomendar fervientemente su lectura pero sin veneración, y haciendo uso y no abuso de él.

Felicitaciones a los compiladores por la excelente tarea.

iAl maestro par excellence con cariño! 